\section{Journal of Memory and Language}

www.elsevier.com/locate/jml

\title{
Dominance affects determiner selection in language production ${ }^{\text {is }}$
}

\author{
Katharina Spalek*, Herbert J. Schriefers \\ NICI, University of Nijmegen, P.O. Box 9104, 6500 HE, Nijmegen, Netherlands
}

Received 9 January 2004; revision received 2 September 2004

\begin{abstract}
Janssen and Caramazza (2003) show that when producing diminutives or plurals in Dutch, determiner information about the corresponding (singular) base form is active. This is reflected in a time cost for producing the plural or the diminutive with a gender-marked determiner when these forms and the corresponding singular or base form require different determiners. No such cost is observed when singular and plural or base form and diminutive require the same determiner. In a series of picture naming experiments we show that this competition effect is modulated by the relative dominance of the morphological forms. The results can be explained within an extension of the "primed unitised activation account" proposed by Alario and Caramazza (2002).
\end{abstract}

(c) 2004 Elsevier Inc. All rights reserved.

Keywords: Determiner selection; Dominance; Diminutives; Plurals

Over the last years, research on lexical access in language production has shifted from single word utterances to more complex utterances like noun phrases (NPs). Like single words, NPs (consisting of, e.g., a determiner and a noun, or a gender-marked adjective and a noun) can easily be elicited by simple picture naming tasks. But in contrast to single words, NPs allow tapping into syntactic processing: In order to produce a determiner NP in a language with gender-marked determiners, a speaker has to access a noun's grammatical gender and to select the appropriate determiner.

\footnotetext{
is The first author received a graduate scholarship of the German Academic Exchange Service (DAAD) during part of the research. We thank three anonymous reviewers for valuable comments on previous versions of the manuscript.

* Corresponding author. Fax: +31 243616066.

E-mail address: k.spalek@nici.ru.nl (K. Spalek).
}

In this paper, we investigate determiner selection within two different morphological domains - diminutive formation and plural inflection. We are especially interested in whether and how determiner selection is affected by the relative frequency (dominance) of a specific morphological form. In order to provide the background for our experiments, we will briefly discuss current theories and experimental evidence on the processing of gender information and the selection of gender-marked determiners in language production. Then we will turn to a recent study on determiner selection in Dutch. These experiments form the point of departure for the present research.

Schriefers (1993) investigated the processing of grammatical gender information in language production in Dutch, using a variant of the picture word interference task. He found longer naming latencies when the distractor's gender differed from the gender of the to-beproduced target noun (incongruent condition) than in 
a condition where target and distractor had the same gender (congruent condition) (for replications in Dutch and German see La Heij, Mak, Sander, \& Willeboordse, 1998; Schiller \& Caramazza, 2003; Schriefers \& Teruel, 2000; van Berkum, 1997). In the framework of the language production model of Levelt and colleagues (Bock \& Levelt, 1994; Jescheniak \& Levelt, 1994; Levelt, 1999), Schriefers interpreted this result as a gender competition effect. In the model, gender is represented as an abstract node at the lemma level. All words of a given gender are linked to their gender node, which is in turn connected to gender-marked lexical items like determiners and pronouns. In the picture word interference task, the incongruent distractor activates a gender different from the one activated by the target word. Solving this competition is thought to be time consuming, leading to longer naming latencies in the incongruent than in the congruent condition where activation from target word and distractor converges on the same gender node.

Miozzo and Caramazza (1999), however, present data suggesting that not abstract gender features compete for selection but rather actual determiners, presumably at the level of phonological form (Miozzo \& Caramazza, 1999, Experiment 4).

Alario and Caramazza (2002) provide further evidence for this position from a study looking at the processing of demonstrative determiners and possessive determiners in French. They found a delay in naming latencies when the phonology of a noun and the grammatical gender of a noun did not support selection of the same gender-marked determiner, as opposed to the case where all available information converged on the choice of the same determiner. The authors explain this in the framework of the so-called primed unitised activation account: Information necessary for selecting the appropriate determiner is collected in a frame. This frame consists of slots for the relevant features. When the frame is completely filled, it sends a burst of activation to the determiner that has to be selected given this particular combination of features. But every single feature that is collected in the frame also sends activation to the determiner with which it is directly linked. Therefore, competing non-target determiners can also receive a certain amount of activation during the selection process.

Additional evidence for determiner competition comes from recent studies in German (Schriefers, Jescheniak, \& Hantsch, 2002, in press) and Dutch (Janssen \& Caramazza, 2003). As the present experiments are conducted in Dutch, we will restrict our discussion to the study by Janssen and Caramazza (2003), which follows the same experimental logic as the study by Schriefers et al. (2002) in German.

In Dutch, the two definite singular determiners de (common gender) and het (neuter gender) converge on $d e$ in the plural. Furthermore, in Dutch the use of dimin- utives is very common and every noun (and even some verbs or prepositions) can be turned into a diminutive by simply adding the ending-tje (or one of its allomorphs). All diminutives are neuter, requiring the definite determiner het, independent of the gender of the corresponding base form. Janssen and Caramazza had participants name the same set of pictures in one experiment with singular and plural NPs and in a second experiment with base form and diminutive NPs. With singular and plural NPs, they found plural costs in naming latencies for het-words (longer naming latencies for plural determiner NPs than for singular determiner NPs), but a plural gain for $d e$-words. In two control experiments, participants named the same pictures with bare nouns or with the numerals een (one) and twee (two) that are not gender marked in Dutch. In these control experiments the gender by number interaction was not obtained.

When contrasting definite determiner NPs of nouns in their base form with definite determiner NPs of nouns in their diminutive form, diminutive het-words did not show a cost relative to their corresponding base form, but diminutive $d e$-words were produced more slowly than their corresponding base form. Here, a note on terminology seems necessary: As pointed out above, all diminutives have neuter gender and thus require the determiner het. But, from here onwards, we will use the term "diminutive $d e$-word" to refer to the diminutive of a word with a common gender base form (i.e., a base form requiring the determiner $d e$ ). The term "diminutive het-word" will be used for the diminutive of a word with a neuter gender base form (i.e., a base form requiring the determiner het).

Janssen and Caramazza explained the results within the primed unitised activation account proposed by Alario and Caramazza (2002). The singular base form is regarded as the default form of the morphological process. It will always activate its associated determiner, that is, het for words of neuter gender, and de for words of common gender. The feature plural activates the determiner $d e$, and any frame including the plural feature eventually leads to the selection of the determiner de. Therefore, for plural het-words there will be competition between the determiners de and het.

Similarly, for diminutives, the feature diminutive activates the determiner het, and any frame including the diminutive feature will also eventually select het. As a result, there will be competition when a diminutive $d e$-word has to be produced. Janssen and Caramazza assume that the base form is accessed by default and is, if necessary, transformed into another form by means of a lexical rule (e.g., "add-tje"). Fig. 1 illustrates this assumption. The diminutive is used as example, but the same kind of mechanism could work for plurals, with one difference: For diminutives, competition might concern abstract gender features or actual determiners, 


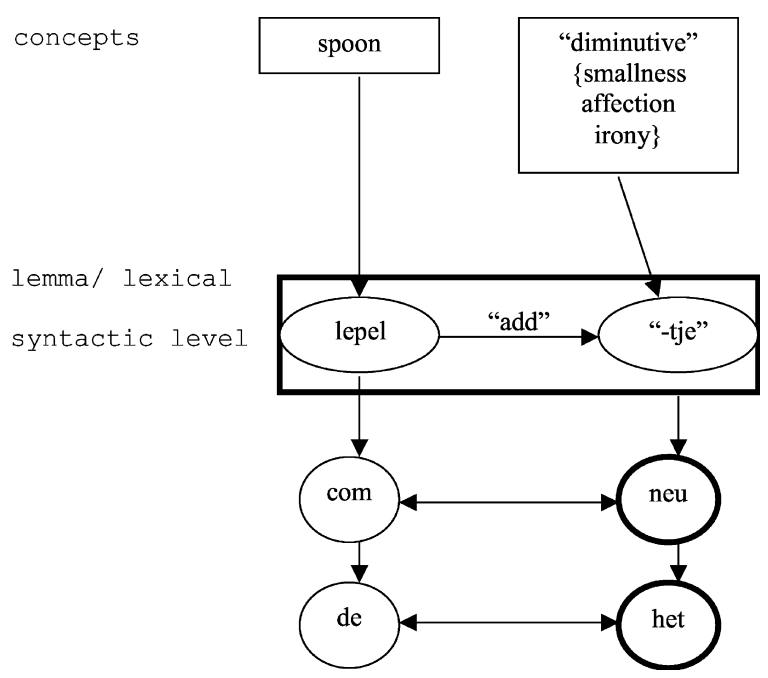

Fig. 1. Coactivation of determiners during diminutive retrieval by applying a lexical rule to the default base form. Doubleheaded arrows signify (possibly) competing elements.

but for plurals the competition necessarily concerns actual determiners, because the transition from singular to plural leaves the grammatical gender unchanged, while for diminutive $d e$-words, the gender changes from common gender for the base form to neuter gender for the diminutive.

Janssen and Caramazza also discuss an alternative account of diminutive access: A base form and a diminutive could be stored independently. The semantic representation of a diminutive will then activate both the diminutive and the base form entry. Fig. 2 illustrates this account.

This second account is more difficult to apply to plural formation, because it implies that the results of noun inflection are stored in the mental lexicon. However,

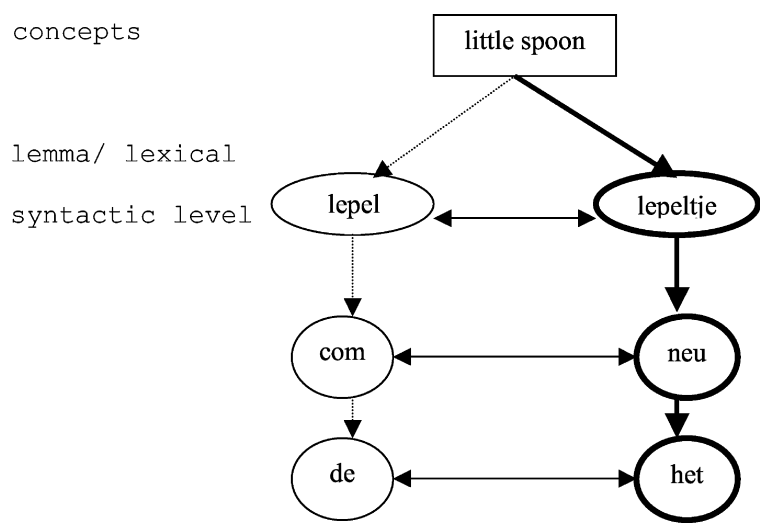

Fig. 2. Separate, coactivated entries for base forms and diminutives during diminutive retrieval. Double-headed arrows signify (possibly) competing elements. there are some indications (Baayen, Dijkstra, \& Schreuder, 1997) that this might actually be the case, at least in language comprehension. No matter whether the scenario of Fig. 1 or Fig. 2 is considered, both imply that the gender and/or the determiner of the default form is visible to the determiner selection process, even when theoretically superfluous, as in the case of producing diminutives or plurals.

The accounts of determiner selection discussed above assume that determiner selection operates in the same way for all instances of a given morphosyntactic class (e.g., all diminutives or all plurals). Yet, a number of observations might challenge this view. First, it has been shown that the relative frequency of the singular and the plural of a noun affects the way in which these words are recognised (e.g., Baayen et al., 1997). Second, with respect to diminutives, which are very frequent in spoken Dutch, not every word has the same predisposition to be used in its diminutive form. There exists a linguistic continuum of diminutives, ranging from lexicalised diminutives over diminutive-dominant to base-form-dominant nouns (Bakema, Defour, \& Geeraerts, 1993; Booij \& van Santen, 1998; de Haas \& Trommelen, 1993). Words from different points of this dominance continuum might be processed differently in the mental lexicon, leading to differences in the determiner selection process in language production. In the present experiments, we addressed this question following the logic of the corresponding experiments of Janssen and Caramazza (2003), with the additional variation of the relative frequency of usage (dominance) of an item as diminutive or base form, and as singular or plural, respectively. Experiment 1 focuses on determiner selection for diminutives and base forms. Experiment 2 studies the effect of dominance on determiner selection for singulars and plurals.

Three opposing views can be conceived with respect to the potential impact of dominance of morphological forms on determiner selection. We will introduce these views here for base form nouns and diminutive nouns, but they apply in the same way to singulars and plurals. All three views assume coactivation of the base form during the production of diminutives of base-form-dominant nouns. This assumption is based on the results obtained by Janssen and Caramazza (2003). The critical question is whether and how diminutive dominance will affect gender and/or determiner competition. From now on, we will use the term determiner competition. We will come back to the question of whether we observe gender or determiner competition in the Discussion of Experiment 1 .

First, all members of a given morphological class could be processed in the same way. Whenever a diminutive is produced, the baseform and its determiner will be activated, even for words with a diminutive preference. Then diminutive dominance should not matter. As a consequence, both types of words (base-form-dom- 
inant and diminutive-dominant words) should show a reaction time cost for selecting the determiner of a diminutive $d e$-word relative to selecting the corresponding base form determiner, and no such cost (or even a gain) for selecting the determiner of diminutive hetwords. We will refer to this as "uniform processing."

Second, the diminutives and the base forms of diminutive-dominant, but not of base-form-dominant nouns could be accessed directly, without activation of the other form. For example, when the concept of a diminutive-dominant word like lepeltje (little spoon) is chosen, it will pass on activation to its lemma lepeltje and the corresponding determiner het only. Therefore, for the selection of the determiner of diminutive-dominant nouns, there should be no interaction between the gender of the base form (common vs. neuter gender, i.e., de- vs. het-word) and produced form (base form vs. diminutive). By contrast, base-form-dominant items would show such an interaction. Note that this hypothesis is an extrapolation for production of the proposal put forward by Baayen et al. (1997) for singular and plural nouns in comprehension. We will call this view "independent entries."

Finally, for diminutive-dominant nouns, the diminutive could be the default access form. Therefore, access to the diminutive of a diminutive-dominant noun and its determiner does not imply activation of its corresponding base form. If, however, the base form of a diminutive-dominant noun has to be accessed, the corresponding diminutive and its determiner will be co-activated. Under this view, for diminutive-dominant nouns, the determiner of the base form would not be visible to the process selecting the determiner of the diminutive form. By contrast, the determiner of the diminutive would be visible to the process selecting the determiner of the base form. Consequently, the selection of the determiner of the base form of a diminutive-dominant de-word (e.g., de lepel) will take longer than the selection of the determiner of the diminutive of a diminutive-dominant de-word (e.g., het lepeltje). The determiner de in de lepel has to compete with the simultaneously activated het from het lepeltje. No effect will be obtained for determiner selection of base form het-words (e.g., het kado (present)) compared to the corresponding diminutive (e.g., het kadootje). Put differently, for diminutive-dominant nouns, we should obtain an interaction of precisely the opposite form than the one predicted for base-formdominant nouns. This view will be called "dominance driven access."

\section{Experiment 1}

Experiment 1 tests determiner competition in the production of base forms and diminutives. It consists of two parts. In Experiment 1a, participants produced gender- marked determiner NPs ("gender condition"); in Experiment $1 \mathrm{~b}$, participants produced indefinite determiner NPs. In Dutch, the indefinite determiner een is not gender marked, and therefore determiner competition cannot play a role in this condition ("no-gender condition"). This baseline was necessary for the following reason: The experimental factors dominance and gender can only be tested between items. Therefore we need to know the naming latencies for all items without selection of gender-marked determiners. ${ }^{1}$ Potential differences between the item groups might be caused by factors like, for example, visual picture processing, word form retrieval, wordlength, and stress pattern. The influence of these factors is independent of utterance type. There is only one additional requirement in Experiment 1a (gender condition), namely the production of a gender-marked determiner. Contrasting the latencies in the no-gender condition (Experiment 1b) with those in the gender condition (Experiment 1a) will filter out the inter-item differences and thus provide us with an estimate of the time needed for selecting the gender-marked determiner.

\section{Method}

\section{Participants}

Seventy-nine native speakers of Dutch participated in Experiment 1. They were students or Ph.D.-students of the University of Nijmegen. Their vision was normal or corrected-to-normal. Participants received course credit or were paid $5 €$. The data of 15 participants (four in Experiment 1a, 11 in Experiment 1b) were excluded from further analyses because of technical problems, because participants did not correctly understand the task or had an overall error score higher than $20 \%$. This yielded 32 participants in Experiment 1a and 32 participants in Experiment 1b.

\section{Materials}

Sixty line drawings of animals and objects were used as experimental stimuli. The drawings were presented in white on a black background and were surrounded by a white frame sized $76 \mathrm{~mm} \times 76 \mathrm{~mm}$. There were two versions of each target picture: The large version of the pic-

\footnotetext{
1 Picture naming studies by La Heij et al. (1998), Schriefers (1993), and others show that gender (in-)congruency effects are only observed when grammatical gender has to be computed in the target utterance. When selecting the indefinite determiner, no gender has to be computed. Indefinite determiner NPs are thus the most appropriate baseline for investigating the selection of gender-marked definite determiners in that indefinite determiner NPs parallel Experiment 1a, as far as a function word has to be placed in front of the to-be-produced noun, but this function word does not depend on the noun's grammatical gender.
} 
ture was sized $76 \mathrm{~mm} \times 76 \mathrm{~mm}$, filling the entire frame. The small version was $38 \mathrm{~mm} \times 38 \mathrm{~mm}$ and was positioned in the centre of the frame. Half of the 60 pictures had base-form-names of common gender (de-words), while the other half had base-form-names of neuter gender (het-words). Twenty stimuli were base-form-dominant, with 10 de-words and 10 het-words. Another 20 stimuli were diminutive-dominant, with $10 \mathrm{de}$-words and 10 het-words. The remaining 20 pictures served as filler stimuli which were intermediate between baseform- and diminutive-dominant stimuli. Ten of these stimuli were $d e$-words and 10 het-words. These fillers will be referred to as "neutral fillers."

\section{Selection of the materials}

An item's dominance was determined in a pretest with 15 native speakers of Dutch (none of whom participated in one of the later experiments). They saw a list of 266 Dutch concrete nouns. Each noun was given in its base form and in its diminutive. Underneath the two forms was a scale from 1 to 7 . Participants rated how often they use the diminutive and how often the base form in informal spoken language (1 being word always used as base form and 7 word always used as diminutive). This rating study was necessary because diminutive usage is predominantly a phenomenon of spoken language and cannot reliably be judged from lexical databases based primarily on written language corpora. On the basis of this pretest, items for the base-form-dominant and the diminutive-dominant group were selected. An item was assigned to the base-form-dominant group when its mean diminutive rating was lower than 2 . This implies that some of these items had been rated with 1 in some of the individual ratings, that is, specific speakers never use them as diminutives or only in highly constrained pragmatic circumstances. An item was assigned to the diminutive-dominant group when its mean rating was equal to or higher than 4. Diminutive-dominant items had to meet a second criterion: They had to be used as a diminutive in at least $10 \%$ of the instances reported in the CELEX database for Dutch (Baayen, Piepenbrock, \& van Rijn, 1993). From the words of our pretest, only $10 \mathrm{de}$-words met the criterion for being diminutive- dominant. This fixed the number of items for the remaining three conditions. For each of them, the 10 best exemplars were chosen (i.e., diminutive rating as low as possible or as high as possible, respectively), trying to keep the average logarithmic lemma frequency between the four conditions as similar as possible. All items used are listed in Appendix A. Note that none of the diminutive-dominant items belonged to the class of fully lexicalised diminutives. They were selected such that the only meaning difference between base form and diminutive concerned the indication of smallness by the diminutive. Table 1 shows the main properties of the selected critical items, broken down by gender of base form (de-vs. het-word) and dominance (baseform- vs. diminutive-dominance). In addition to the mean rating in the pretest, Table 1 shows the range of mean ratings, the proportion of diminutives within all usages of the word according to CELEX, and the mean logarithmic lemma frequencies per million.

Ratings, proportions according to CELEX, and logarithmic lemma frequencies were submitted to analyses of variance with the factors dominance (base-form- vs. diminutive-dominant) and gender of base form (de-vs. het-word). The pretest ratings of base-form-dominant and diminutive-dominant items differed significantly, $F(1,36)=581.60, p<.001, M S E=0.19$. There was also a significant difference between the ratings for $d e$ - and het-words, $F(1,36)=6.94, p<.05, M S E=0.19$. The interaction of dominance and gender of base form for ratings was significant, $F(1,36)=6.75, p<.05, M S E=0.19$.

The main effects for CELEX proportion were significant for both dominance, $F(1,36)=63.47, p<.001$, $M S E=62.71$, and gender of base form, $F(1,36)=5.27$, $p<.05, M S E=62.71$. Here, too, the interaction of dominance and gender of base form was significant, $F(1,36)$ $=5.27, p<.05, M S E=62.71$.

Because of the restrictions in the choice of appropriate items mentioned above, we could not avoid a significant difference in logarithmic lemma frequency between the groups: Diminutive-dominant words were more frequent $(\log$ frequency $=1.3)$ than base-form-dominant words $(\log$ frequency $=.79), F(1,36)=13.21, p<.01$, $M S E=0.2$. Yet, there was no main effect of gender of

Table 1

Mean ratings, range of mean ratings, mean CELEX proportions of diminutives, and mean logarithmic frequencies (of frequency $\mathrm{p} / \mathrm{m}$ ) for experimental items of Experiment 1

\begin{tabular}{llllrr}
\hline Condition & & Rating & Range & CELEX (\%) & Log frequency \\
\hline Dominance & Gender of base form & & & & \\
\hline Base form & Common (de-words) & 1.31 & $1.07-1.63$ & 1.1 & .67 \\
& Neuter (het-words) & 1.32 & $1.07-1.87$ & 1.1 & .91 \\
Diminutive & Common (de-words) & 4.24 & $4.00-4.63$ & 15.3 & 1.34 \\
& Neuter (het-words) & 4.95 & $4.07-6.13$ & 26.8 & 1.28 \\
\hline
\end{tabular}


base form on logarithmic frequency $(F<1)$ and no interaction of dominance and gender of base form, $F(1,36)=1.13, p=.294, M S E=0.2$.

\section{Design}

Three factors were completely crossed: The two-level factor gender of base form (de-vs. het-word), the two-level factor dominance (base-form- vs. diminutive-dominant), and the two-level factor produced form (base form vs. diminutive). Gender of base form and dominance were between-item factors; produced form was tested within items. The main experiment consisted of two blocks. In block 1, 30 items were presented as large pictures, eliciting a base-form-response, and 30 items were presented as small pictures, eliciting a diminutiveresponse. In block 2 , the presentation was reversed, such that a picture that had previously been presented as a small picture, was now shown in large size and vice versa. Therefore each picture was named once as a base form and once as a diminutive. Because in Experiment 1a (gender condition) a diminutive is always accompanied by the determiner het, there were 45 instances of responses requiring the determiner het per block (30 diminutives and 15 het-word base forms), but only 15 responses requiring the determiner $d e$. In order to avoid a response bias for het, in each block 30 large pictures with $d e$-word names were used as additional fillers (adding 30 more de-responses). The entire experiment consisted of two blocks with 90 items each. The presentation of the pictures was pseudo-randomised according to the following constraints: No more than three pictures of the same size followed each other, subsequent pictures were neither semantically nor phonologically related, and the same determiner was never produced more than three times in a row. Half of the participants saw block 1 first, followed by block 2; for the other half of the participants, the order of blocks was reversed. The same lists were used in Experiments 1a and 1b.

\section{Apparatus and procedure}

Each participant was tested individually in a session lasting about $50 \mathrm{~min}$. The participant was seated in a dimly lit room, separated from the experimenter by a partition wall. The experiment was controlled by an Intel Pentium $166 \mathrm{MHz}$ computer. The visual stimuli were presented centred on a 17 in. SVGA monitor at a resolution of $640 \times 480$ pixels. Viewing distance was about $80 \mathrm{~cm}$. The presentation of the stimuli and the on-line collection of data were controlled by a Pentium computer. Speech-onset latencies were measured to the closest millisecond with a voice key connected to the computer. Participants' responses were recorded with a SONY ZA5ES DAT recorder.

The session consisted of three parts. In the first part the participants were familiarised with the pictures: They saw all pictures once on the screen. All pictures were shown in large size. A picture was presented for $3250 \mathrm{~ms}$. Two thousand two hundred and fifty milliseconds after picture onset the name was written on top of the picture frame, where it stayed on for $750 \mathrm{~ms}$ after the picture had disappeared. The familiarisation was done to increase name agreement and to acquaint participants with the size of the large pictures. After having gone through the presentation of the material, participants received the written instruction for the main part of the experiment. This was the only point in which Experiments $1 \mathrm{a}$ and $1 \mathrm{~b}$ differed. Participants of Experiment 1a were told to name the pictures with a NP consisting of the definite determiner and the noun, whereas participants of Experiment $1 \mathrm{~b}$ were instructed to name the pictures with a NP consisting of the indefinite determiner een and a noun. Furthermore, all participants were told that pictures could either have the same size as in the familiarisation or appear in a much smaller size. They were instructed to name the small pictures with diminutive NPs and the large pictures with base form NPs.

The main experiment was preceded by a practice block consisting of 18 trials. A trial started with a fixation cross presented in the centre of the screen for $800 \mathrm{~ms}$. After a blank lasting $200 \mathrm{~ms}$ a picture was shown for $1500 \mathrm{~ms}$. A participant's naming latencies were measured from picture onset. The trial stopped $2000 \mathrm{~ms}$ after picture onset.

After the experiment, participants filled in a rating form similar to the one used in the pretest for the materials. Only the target items of Experiment 1 were included. This rating allowed us to assess whether participants' intuitions about the items' dominance corresponded with the assignment of the items to the experimental conditions.

\section{Results}

A participant's response was coded as erroneous when a wrong word, a wrong form (e.g., a diminutive instead of a base form or vice versa) or a wrong determiner was used, when hesitations or corrections occurred, when no reaction had taken place within $2000 \mathrm{~ms}$, and when the voice key was triggered by a non-speech sound.

A participant produced every experimental item twice, once as base form and once as diminutive. When one of these forms had been coded as an error, the other response for the same picture and participant was also excluded from the reaction time analyses. ${ }^{2}$

\footnotetext{
${ }^{2}$ For this and all following experiments, we also carried out the statistical analyses before excluding items as pairs. The results of these analyses were the same as those reported for the pairwise exclusion.
} 
Table 2a

Mean naming latencies in milliseconds and error percentages for base-form-dominant words in Experiments $1 \mathrm{a}$ and $1 \mathrm{~b}$ (standard deviations in brackets)

\begin{tabular}{llll}
\hline Gender of base form & & Produced form & \multicolumn{1}{c}{ Diminutive } \\
\cline { 3 - 4 } & & Base form & $1039(166) 29 \%$ \\
\hline Common $(d e$-words) & Experiment 1a & $984(121) 13 \%$ & $892(122) 23 \%$ \\
Difference $(1 \mathrm{a}-1 \mathrm{~b})$ & Experiment 1b & $893(135) 13 \%$ & 147 \\
Neuter $($ het-words) & & 91 & $913(109) 13 \%$ \\
Difference $(1 \mathrm{a}-1 \mathrm{~b})$ & Experiment 1a & $923(98) 14 \%$ & $904(141) 17 \%$ \\
\hline
\end{tabular}

Table $2 b$

Mean naming latencies in milliseconds and error percentages for diminutive-dominant words in Experiments $1 \mathrm{a}$ and $1 \mathrm{~b}$ (standard deviations in brackets)

\begin{tabular}{llll}
\hline Gender of base form & & Produced form & \multicolumn{1}{c}{ Diminutive } \\
\cline { 3 - 4 } & & Base form & $926(114) 17 \%$ \\
\hline Common $(d e$-words) & Experiment 1a & $935(124) 14 \%$ & $858(129) 12 \%$ \\
Difference $(1 \mathrm{a}-1 \mathrm{~b})$ & Experiment 1b & $841(127) 9 \%$ & 68 \\
Neuter $(h e t$-words) & & 94 & $900(117) 17 \%$ \\
Difference $(1 \mathrm{a}-1 \mathrm{~b})$ & Experiment 1a & $957(148) 18 \%$ & $891(138) 18 \%$ \\
\hline
\end{tabular}

Furthermore, observations deviating from a participant's and an item's mean within an experimental condition by more than two standard deviations were considered as outliers and discarded from the reaction time analyses. For Experiment 1a, 17\% of the responses to the experimental items were coded as errors and $1 \%$ as outliers. For Experiment $1 \mathrm{~b}$, there were $15 \%$ errors $^{3}$ and $0.8 \%$ outliers. Mean naming latencies and error percentages are shown in Tables $2 \mathrm{a}$ and $2 \mathrm{~b}$ for base-formdominant and diminutive-dominant nouns, respectively.

We carried out separate analyses of variance for base-form-dominant nouns and for diminutive-dominant nouns, with the factors Experiment (1a, gender condition, vs. 1b, no-gender condition), gender of base form (de- vs. het-word), and produced form (base form vs. diminutive). In the participant analysis, Experiment is a between-participants factor, and gender and form are within-participants factors. In the item analysis, Experiment and form are within-items factors, and gender is a between-items factor. In these analyses, an inter-

\footnotetext{
3 The proportion of erroneous responses was high for a simple picture naming task, both in the main experiment and in the baseline. This is presumably due to the fact that we could not use standardised pictures with high name agreement. The fact that error rates are high in the baseline, too, suggests that participants did not have specific problems with the task of producing definite determiner NPs.
}

action of Experiment with any of the other factors indicates that the difference between Experiments 1a and $1 \mathrm{~b}$ systematically varies with the levels of the respective factor. As a visualisation of the interactions, Fig. 3 therefore shows the difference values [Experiment 1aExperiment $1 \mathrm{~b}$ ] as a function of gender of base form and produced form.

The main focus of interest lies on the three-way interaction of Experiment by gender by produced form. We will mention the two-way interactions of Experiment by gender and of Experiment by form, but we will only discuss the three-way interaction in detail. For base-formdominant items, there was a significant interaction of Experiment and gender of base form, $F_{1}(1,62)=29.85$, $p<.001, M S E=4807, F_{2}(1,18)=11.48, p<.01, M S E$ $=2978$. There was no interaction of Experiment and produced form, $F \mathrm{~s}<1$. The critical interaction of Experiment, gender of base form, and produced form was also significant, $\quad F_{1}(1,62)=6.97, \quad p<.01, \quad M S E=4226$, $F_{2}(1,18)=12.45, p<.01, M S E=1565$. This interaction reflects the fact that for de-words the difference between Experiments $1 \mathrm{a}$ and $1 \mathrm{~b}$ is increased from $91 \mathrm{~ms}$ for base form utterances to $147 \mathrm{~ms}$ for diminutive utterances, whereas for het-words, the corresponding difference is reduced from 39 to $9 \mathrm{~ms}$. The former increase of $56 \mathrm{~ms}$ is significant, $F_{1}(1,62)=3.96, p<.05, M S E=6504, F_{2}(1,9)$ $=6.16, p<.05, M S E=2292$, while the latter reduction of $30 \mathrm{~ms}$ is not significant by participants, $p>.1$, but sig- 


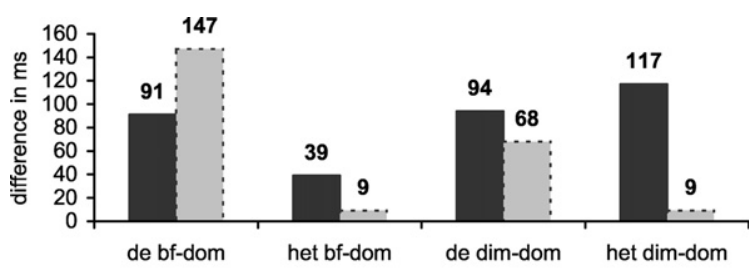

base form : idiminutive

Fig. 3. Mean naming latency differences of Experiment 1a (production of gender-marked definite base form and diminutive NPs) minus mean naming latencies of Experiment $1 \mathrm{~b}$ (production of indefinite base form and determiner NPs with non-gender-marked indefinite determiners). Note. de: common gender nouns; het: neuter gender nouns; bf-dom: base-form dominant; dim-dom: diminutive dominant.

nificant by items, $F_{2}(1,9)=7.36, p<.05, M S E=838$. Put differently, there is a significant diminutive cost for $d e$-words, but a slight gain for het-words.

For diminutive-dominant items, there was no interaction of Experiment and gender of base form, $p \mathrm{~s}>.1$. The interaction of Experiment and produced form was significant, $F_{1}(1,62)=16.58, p<.001, M S E=4297, F_{2}(1,18)$ $=18.62, p<.001, M S E=1729$. The critical interaction of Experiment, gender of base form, and produced form was also significant, $F_{1}(1,62)=6.14, p<.05, M S E=$ $4413, F_{2}(1,18)=9.63, p<.01, M S E=3458$. In this condition, for $d e$-words the difference between Experiments $1 \mathrm{a}$ and $1 \mathrm{~b}$ is reduced from $94 \mathrm{~ms}$ for base form utterances to $68 \mathrm{~ms}$ for diminutive utterances. For het-words, the corresponding reduction goes from 117 to $9 \mathrm{~ms}$. The former reduction of $26 \mathrm{~ms}$ is not significant, $p \mathrm{~s}>.2$, while the latter reduction of $108 \mathrm{~ms}$ is significant, $F_{1}(1,62)=16.48$, $p<.001, \quad M S E=5650, \quad F_{2}(1,9)=22.16, \quad p<.001$, $M S E=2146$.

Errors were submitted to the same analyses of variance. The only significant effect was found in the participant analysis for base-form-dominant items, an interaction of Experiment, gender of base form, and produced form, $F_{1}(1,62)=6.68, p<.01, M S E=0.012$, mirroring the naming latencies. This interaction was not significant by items, $F_{2}(1,18)=3.3, p<.086$, $M S E=0.008$.

Upon completion of the experiment, participants filled in a rating similar to the pretest dominance ratings. The correlation of the mean ratings per critical item between the pretest and the ratings provided by the participants in the present experiment was .93, both for Experiment 1a and for Experiment 1b, indicating that the assignment of items to the base-form-dominant and diminutive-dominant condition was also representative for the participants tested in the present experiments.

\section{Discussion}

As we are not interested in the data of Experiments 1a and $1 \mathrm{~b}$ separately, but only in the naming latencies of Experiment 1a relative to those of 1b, we will phrase the discussion in terms of the difference scores [Experiment 1a-Experiment 1b] as they are given in Fig. 3. In terms of our statistical analyses, differences between these difference scores are reflected in interactions of the factor Experiment with the respective relevant other factors. For base-form-dominant nouns, the data provide support for determiner competition in the production of diminutive NPs: When the determiner of the base form differs from the determiner of the produced diminutive form, naming latencies are prolonged, for example for het fakkeltje (little torch) compared to de fakkel. No statistical difference is found for het-words like het skeletje (little skelaton) and het skelet, where the base form and the diminutive require the same determiner. This replicates the pattern found by Janssen and Caramazza (2003) with different materials.

For diminutive-dominant items, the difference scores also vary as a function of gender of base form and produced form (reflected in statistical terms as an interaction of experiment, gender of base form, and produced form). However, in contrast to base-form-dominant nouns, this interaction is caused by a large facilitation for producing diminutive-dominant het-words as diminutives as compared to producing them as base forms. There is no significant difference in difference scores for $d e$-words produced as base form or as diminutive. The important finding is a clear difference in the pattern of results within a given domain, base forms and diminutives, as a function of the relative dominance of the different morphological forms.

The results for the diminutive-dominant items are in conflict with all three theoretical views introduced earlier. The uniform processing account had predicted the same pattern for base-form-dominant and diminutive-dominant nouns. This is not the case. Under the independent entries hypothesis, there should be no cost for selecting the determiner of a diminutive de-word, which is in accordance with our results. But this hypothesis does not predict the obtained facilitation for selecting the determiner of diminutive-dominant het-words when produced as diminutives. Dominance driven access predicts an interaction of Experiment, gender of base form, and produced form, but this interaction should be due to a cost for selecting the determiner of a base form $d e$-word as compared to the corresponding diminutive form. The actual interaction, though, is caused by a facilitation for selecting the determiner of a diminutive het-word.

Taken together, the form of the interaction for diminutive-dominant items implies that the gender of the base form becomes activated, even in the case of words with a strong diminutive preference. None of 
our hypothetical scenarios correctly predicts the obtained data pattern. We will come back to this point in the General Discussion and show how an adapted version of the primed unitised activation account of Alario and Caramazza (2002) can explain the data.

Before moving on, we should address one possible caveat. In Experiment 1b, all NPs started with the same sound. This was not the case for Experiment 1a. If there were systematic differences between the voice key triggering for de and for het, this might challenge our interpretation of the data. Therefore, we ran a delayed naming task with 36 native Dutch speakers. They read a word on the screen and were instructed to name it after a cue. The cue was presented at three delay intervals, 500, 1000, and $1500 \mathrm{~ms}$. All experimental items appeared after a delay of $1500 \mathrm{~ms}$, after which lexical factors such as wordlength and frequency no longer influence naming latencies (Balota \& Chumbley, 1985). Thus we could assess the pure difference in voice key sensitivity between de and het. This difference was $7 \mathrm{~ms}$, with average latencies of $435 \mathrm{~ms}$ for NPs starting with het and $442 \mathrm{~ms}$ for NPs starting with de. Therefore our effects cannot be caused by differences in the voice key's sensitivity to the determiners de and het.

Experiment 1 does not address the question whether we observe determiner or gender competition, because for base forms and diminutives, any potential determiner competition also implies a competition between gender features. By contrast, looking at competition effects in the production of singular and plural NPs (e.g., Janssen \& Caramazza, 2003; Schriefers et al., 2002, Schriefers, Jescheniak, \& Hantsch, in press) will allow to investigate determiner competition without gender competition. As indicated in the introduction, Dutch has two definite singular determiners, de for common gender and het for neuter gender. In the plural, the definite determiner for both gender classes is $d e$. The competition effects observed by Janssen and Caramazza (2003) for plural NPs of neuter gender nouns (see also Schriefers et al., 2002, in press, for German) cannot be due to gender competition but must be due to determiner competition. In Experiment 2 , we will investigate the potential role of singular and plural dominance in determiner selection during the production of singular and plural NPs.

Just as there are diminutive-dominant words, there also exist words that are more often used as plurals than others. Some nouns occur frequently in their plural form, either because the corresponding concept belongs to a natural pair (e.g., eyes or hands) or because it is often encountered in a flock (e.g., sheep). In some languages plural-dominant words even have a special morphological status (see Baayen et al., 1997, p. 113).

Baayen et al. (1997) showed that singular- and pluraldominance affects the processing of singular and plural nouns in language comprehension. Experiment 2 addresses the question whether singular- vs. plural-domi- nance also modulates the process of determiner selection in language production.

\section{Experiment 2}

Experiment 2 consists of two parts. In Experiment 2a, participants named pictures with singular and plural NPs with the gender-marked definite determiner and a noun (gender condition). In Experiment 2b, a different group of participants named the same pictures with singular and plural NPs and the numerals een (one) and twee (two) which are not gender-marked in Dutch (no-gender condition). For singular-dominant words, we expect determiner competition, based on the results obtained by Janssen and Caramazza (2003) and Schriefers et al. (2002). That is, we expect longer naming latencies (or more precisely, larger differences between naming latencies in Experiments $2 \mathrm{a}$ and $2 \mathrm{~b}$ ) for het-words as plural NPs compared to the singular than for $d e$-words as plural NPs compared to the singular. For plural-dominant words, we want to see whether the pattern changes in a way similar to Experiment 1, that is, a reduction of the cost for het-words as plurals and a gain for $d e$-words as plurals.

\section{Method}

\section{Participants}

Sixty-eight participants from the same subject pool as in Experiment 1 took part in Experiment 2. None of them had participated in Experiment 1. Four participants were excluded (two in Experiment 2a, and two in Experiment $2 b)$ because of technical problems or because they had error rates higher than $20 \%$. This yields 32 participants in Experiment $2 \mathrm{a}$ and 32 participants in Experiment $2 \mathrm{~b}$.

\section{Materials}

Ten line drawings with singular-dominant $d e$-words as names were used, 10 with plural-dominant $d e$-words, 10 with singular-dominant het-words and 10 with pluraldominant het-words. Stimuli were presented as pairs of (identical) pictures. The pictures were either both black (RGB: 00 0; in the system used, RGB colour codes vary from 0 to 63), cueing a plural response, or one black and one grey (RGB: 4242 42), cueing a singular response. They were presented on a light grey background (RGB: 606060 ). This double-object presentation was used in order to make superficial visual number cues less salient (see also Schriefers et al., 2002, in press).

Singular- and plural-dominance was determined from the CELEX database for Dutch. A dominance value was computed by dividing the frequency of singular occurrences of a word by the frequency of its plural occurrences. Items were assigned to the plural-dominant group when this value was smaller than 1 , meaning that the respective word occurs as a plural in more than half of the instances. 
Table 3

Mean dominance value, mean range of dominance values, and mean logarithmic frequencies (of frequency per million) for experimental items of Experiment 2

\begin{tabular}{lllll}
\hline Condition & Gender & Dominance & Range & Frequency \\
\hline \multirow{2}{*}{ Singular } & Common & 11.42 & $4.4-23.04$ & 1.59 \\
& Neuter & 12.73 & $5.08-36.9$ & 1.43 \\
\multirow{2}{*}{ Plural } & Common & 0.55 & $.21-.88$ & 1.51 \\
& Neuter & 0.57 & $.28-.91$ & 1.43 \\
\hline
\end{tabular}

Items were assigned to the singular-dominant group when their value was greater than 4 . For each condition, 10 items were chosen. Plural-dominant items had a mean dominance value of .2, the average score of singular-dominant items was 8.86. Table 3 shows the mean dominance value, range of dominance values, and mean logarithmic lemma frequency per condition.

Dominance values and logarithmic lemma frequencies were submitted to analyses of variance with the factors dominance (singular- vs. plural-dominant) and gender (de- vs. het-word). The dominance values of singularand plural-dominant items differed significantly from one another, $F(1,36)=32.157, p<.001, M S E=41$. There was no significant difference between dominance for $d e$ - and het-words, $F<1$. The interaction of dominance and gender was not significant, either, $F<1$. There were no significant effects of lemma frequency. Appendix B lists all items used in Experiment 2.

\section{Design}

Three two-level factors were completely crossed: gender (de- vs. het-words), dominance (singular- vs. pluraldominant), and number (singular vs. plural). Gender and dominance were between-item factors; number was tested within items. The main experiment consisted of two blocks. In block 1, half of the critical items was presented as singulars, and the other half was presented as plurals. In block 2 , the presentation was reversed, such that a picture that had before been presented as a singular was now shown as a plural and vice versa. Because a plural always requires the determiner $d e$, there were 30 responses requiring the determiner $d e$ per block (20 plurals and 10 $d e$-word singulars), but only 10 responses requiring the determiner het. In order to avoid a response-bias for de, in each block 20 singular pictures with het-words as names were used as fillers (adding 20 more het-responses). In total, each block consisted of 60 items. The presentation of the pictures was pseudo-randomised such that no more than five subsequent trials had the same gender, the same dominance, or required the same determiner. Subsequent trials were neither semantically nor phonologically related. Four experimental lists were created: In two lists block 1 was presented first, followed by block 2, in the other two lists the order was reversed. In the two lists with the same order of blocks, in one list half of the singular items was presented with the grey object on the left and the black object on the right, the other half of the singular items was presented with the black object on the left and the grey object on the right. In the other list, this assignment was reversed.

\section{Apparatus and procedure}

The same apparatus was used as in Experiment 1. Participants were tested individually in a session lasting about $20 \mathrm{~min}$. The session consisted of a familiarisation phase, a practice phase, and the main experiment. During the familiarisation phase, pictures were presented on the screen as single objects with black outline for $3250 \mathrm{~ms}$. Two thousand two hundred and fifty milliseconds after picture onset the name was written on top of the picture frame and it stayed on the screen for $750 \mathrm{~ms}$ after the picture had vanished. Participants were instructed to read the picture names out loud. After the familiarisation with the material, participants received a written instruction for the main experiment, which explained the double object presentation. Participants of Experiment 2a were instructed to name the pictures with definite singular or plural NPs, while participants of Experiment $2 b$ were instructed to use the numerals een and twee in their responses. Before the main session, participants received 18 practise trials. On each trial, a fixation cross was shown in the centre of the screen for $800 \mathrm{~ms}$. After a blank of $200 \mathrm{~ms}$ the two pictures were shown centred on the screen with a distance of about $675 \mathrm{~mm}$ between pictures. The size of the individual pictures was about $4 \times 4 \mathrm{~cm}$. The pictures stayed on the screen for $1000 \mathrm{~ms}$. After another $1500 \mathrm{~ms}$ the next trial started.

\section{Results}

A participant's response was coded as erroneous when a wrong word, a wrong form (e.g., a singular instead of a plural or vice versa), or a wrong article was used, when hesitations or corrections occurred, when no reaction had taken place within $2000 \mathrm{~ms}$, and when the voice key was triggered by a non-speech sound.

A participant produced every experimental item twice, once as singular and once as plural. When one of these forms had been produced as an error, the other form for the same picture was also excluded from the reaction time analyses. ${ }^{4}$

Furthermore, observations deviating from a participant's and an item's mean by more than two standard

\footnotetext{
${ }^{4}$ As in Experiment 1, we also analysed the data without pairwise exclusion of the errors. The descriptive pattern was the same, as were the statistical tests, with the one exception that in the analysis without pairwise exclusion, the interaction of Experiment, gender, and number was significant for singulardominant nouns, $F_{1}(1,62)=6.625, p<.05, M S E=2198$, $F_{2}(1,18)=10.325, p=.01, M S E=743$.
} 
Table $4 \mathrm{a}$

Mean naming latencies and standard deviations (in brackets) in ms and error percentages for singular-dominant words in Experiments $2 \mathrm{a}$ and $2 \mathrm{~b}$

\begin{tabular}{llll}
\hline Gender & & Number & \multicolumn{1}{c}{ Plural } \\
\cline { 3 - 4 } & & Singular & $825(113) 5 \%$ \\
Common (de-words) & Experiment 2a & $845(114) 6 \%$ & $708(79) 6 \%$ \\
Difference $(2 \mathrm{a}-2 \mathrm{~b})$ & Experiment 2b & $704(87) 8 \%$ & 117 \\
Neuter $($ het-words) & & 141 & $875(113) 13 \%$ \\
Difference $(2 \mathrm{a}-2 \mathrm{~b})$ & Experiment 2a & $838(114) 7 \%$ & $734(65) 16 \%$ \\
\hline
\end{tabular}

Table $4 \mathrm{~b}$

Mean naming latencies and standard deviations (in brackets) in ms and error percentages for plural-dominant words in Experiments $2 \mathrm{a}$ and $2 \mathrm{~b}$

\begin{tabular}{|c|c|c|c|}
\hline \multirow[t]{2}{*}{ Gender } & & \multicolumn{2}{|l|}{ Number } \\
\hline & & Singular & Plural \\
\hline \multirow[t]{2}{*}{ Common (de-words) } & Experiment $2 \mathrm{a}$ & 871 (104) $12 \%$ & 801 ( 97) 3\% \\
\hline & Experiment $2 \mathrm{~b}$ & 677 ( 80$) 4 \%$ & 695 ( 74) 4\% \\
\hline Difference $(2 a-2 b)$ & & 194 & 106 \\
\hline \multirow[t]{2}{*}{ Neuter (het-words) } & Experiment $2 \mathrm{a}$ & 844 (108) 12\% & 827 (123) 13\% \\
\hline & Experiment $2 b$ & 716 ( 69$) 8 \%$ & 727 ( 78$) 10 \%$ \\
\hline Difference $(2 a-2 b)$ & & 128 & 100 \\
\hline
\end{tabular}

deviations were considered as outliers and discarded from the reaction time analyses.

For Experiment 2a, $8 \%$ of the responses to the experimental items were coded as errors and $2 \%$ as outliers. For Experiment 2b, there were 8\% errors and 1\% outliers. Mean naming latencies and error percentages are shown in Tables $4 \mathrm{a}$ and $4 \mathrm{~b}$ for singular-dominant and plural-dominant nouns, respectively.

The analyses follow the same logic as in Experiment 1 : We analysed singular-dominant and plural-dominant items separately and we computed three-way ANOVAs with the factors Experiment, gender, and number. As a visualisation of the interactions, Fig. 4 shows the differ-

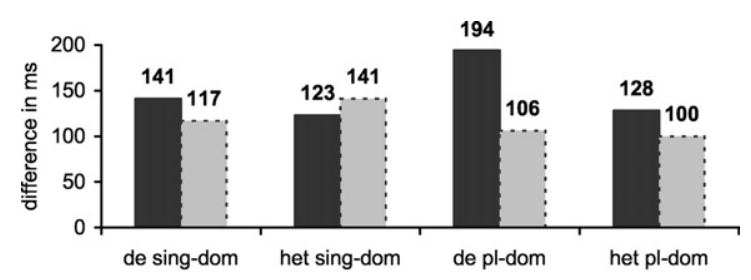

Esingular isplural

Fig. 4. Mean naming latency differences of Experiment 2a (production of gender-marked definite singular and plural NPs) minus mean naming latencies of Experiment $2 b$ (production of singular and plural NPs with non-gender-marked numerals). Note. de: common gender nouns; het: neuter gender nouns; sing-dom: singular dominant; pl-dom: plural dominant. ence values [Experiment $2 \mathrm{a}$ - Experiment $2 \mathrm{~b}$ ] as a function of gender and number.

Again, the main focus is on the results for the threeway interaction of Experiment, gender, and number. For singular-dominant words, there were no significant main effects, no significant interactions of the relevant factors with Experiment and, most importantly, no three-way interaction of Experiment, gender, and number, $p \mathrm{~s}>1 .{ }^{5}$ Descriptively, for $d e$-words the difference between Experiments $2 \mathrm{a}$ and $2 \mathrm{~b}$ is reduced from $141 \mathrm{~ms}$ for singular utterances to $117 \mathrm{~ms}$ for plural utterances, whereas for het -words, the corresponding difference is increased from $123 \mathrm{~ms}$ for singular utterances to $141 \mathrm{~ms}$. However, neither the $24 \mathrm{~ms}$ reduction nor the $18 \mathrm{~ms}$ increase were significant.

For plural-dominant items, there was an interaction of Experiment and gender, $F_{1}(1,62)=8.28, \quad p<.01$, $M S E=2406, F_{2}(1,18)=5.23, p<.05, M S E=890$. The interaction of Experiment and number was significant, $F_{1}(1,62)=26.22, \quad p<.001, \quad M S E=2046, \quad F_{2}(1,18)=$ 30.69, $p<.001, M S E=598$. Most importantly, the

\footnotetext{
5 The only two effects with $p$-values smaller than .10 in either the $F_{1}$ or the $F_{2}$ analysis are the interaction of Experiment, gender, and number, $F_{1}(1,62)=2.86, p=.096, M S E=2396$, $F_{2}(1,18)=2.84, p=.1, M S E=1053$, and the $24 \mathrm{~ms}$ gain for producing $d e$-words as plurals, compared to producing them as singulars, $F_{1}(1,62)=2.15, \quad p=.15, \quad M S E=2153$, $F_{2}(1,9)=3.72, p=.086, M S E=502$.
} 
three-way interaction of Experiment, gender, and number was significant, $F_{1}(1,62)=7.3, p<.01, M S E=2006$, $F_{2}(1,18)=5.81, p<.05, M S E=598$. This interaction reflects the fact that for $d e$-words the difference between Experiments $2 \mathrm{a}$ and $2 \mathrm{~b}$ is reduced from $194 \mathrm{~ms}$ for singular utterances to $106 \mathrm{~ms}$ for plural utterances, whereas for het-words, the corresponding reduction is only from 128 to $100 \mathrm{~ms}$. The former reduction of $88 \mathrm{~ms}$ is significant, $F_{1}(1,62)=39.61, \quad p<.001, \quad M S E=1570, \quad F_{2}(1,9)=$ $49.75, p<.001, M S E=379$, while the latter reduction of $28 \mathrm{~ms}$ is not, $F_{1}(1,62)=2.46, p=.122, M S E=2482$, $F_{2}(1,9)=3.59, p=.091, M S E=816$. Put differently, we see a significant plural gain for $d e$-words, but not for het-words.

Error rates were submitted to the same ANOVAs. For singular-dominant items, no significant effects were found (all $p \mathrm{~s}>.2$ ). For plural-dominant items, there was a significant interaction of Experiment and number, $F_{1}(1$, $62)=6.964, p<.01, M S E=0.006, \quad F_{2}(1,18)=5.236$, $p<.05, M S E=0.002$. The interaction of Experiment, gender, and number was not significant, $F_{1}(1,62)=$ $2.985, p<.089, M S E=0.008, F_{2}(1,18)=2.945, \quad p=$ $.103, M S E=0.002$.

\section{Discussion}

For singular-dominant nouns, descriptively, we see the expected Experiment by gender by number interaction. It takes longer to select the determiner for het-words as plural NPs relative to the singular whereas there is no difference or even a slight gain for selecting the determiner for $d e$-words as plurals. However, statistically this interaction is not significant. Thus we fail to replicate what we considered as the basic pattern (as reported by Janssen \& Caramazza, 2003 and Schriefers et al., 2002, in press).

For plural-dominant nouns, we find a significant Experiment by gender by number interaction. This interaction is caused by a substantial gain for selecting the determiner of $d e$-words as plurals as compared to the singular. However, one could suspect that this interaction is primarily caused by one specific data point, namely the difference value of $194 \mathrm{~ms}$ for $d e$-words as singulars. This condition shows the slowest naming latencies with definite determiner NPs (Experiment 2a) and the fastest naming latencies with numerals (Experiment $2 b$ ). In order to exclude the possibility that the results were due to some unknown special property of the baseline with numerals (Experiment $2 \mathrm{~b}$ ), we conducted a second baseline experiment, Experiment 2c. Another 32 participants named the pictures, this time with singular and plural bare nouns. Participants responded more slowly in this condition than in the condition with numerals. The overall pattern does not change much, though. If we compare the difference scores for Experiments $2 \mathrm{a}$ and $2 \mathrm{~b}$ with those for Experiments $2 \mathrm{a}$ and $2 \mathrm{c}$, the following picture arises: For singular-dominant nouns, the gain for $d e$-words as plurals changes from 24 to $37 \mathrm{~ms}$, and the cost for het-words as plurals changes from 18 to $21 \mathrm{~ms}$. Now the Experiment by gender by number interaction is significant, $F_{1}(1,62)=5.77, p<.05, M S E=2303$, $F_{2}(1,18)=8.56, p<.01, M S E=633$. The $37 \mathrm{~ms}$ gain for $d e$-words is also significant in this analysis, $F_{1}(1,62)=$ $5.71, p<.05, M S E=1928, \quad F_{2}(1,9)=13.14, p<.01$, $M S E=235$. For plural-dominant items, the $88 \mathrm{~ms}$ gain for $d e$-words becomes a $92 \mathrm{~ms}$ gain, and the $28 \mathrm{~ms}$ gain for het-words becomes a $38 \mathrm{~ms}$ gain. In contrast to the analyses of Experiments $2 \mathrm{a}$ and $2 \mathrm{~b}$, the experiment by gender interaction is no longer significant by items, $p>.2$, and the Experiment by gender by number interaction is no longer significant by items, $F_{2}(1,18)=3.96$, $p=.062, M S E=949$. All other effects are the same as in the analysis of Experiments $2 \mathrm{a}$ and $2 \mathrm{~b}$. To summarise, introducing a different baseline (bare nouns instead of numerals) does not affect the overall descriptive pattern of data. The statistical pattern, however, changes. When considering the difference between determiner NPs and the numeral baseline (Experiments $2 \mathrm{a}$ and $2 \mathrm{~b}$ ), the critical interaction is absent for singular-dominant nouns and present for plural-dominant nouns. When using the bare noun baseline (Experiments 2a and 2c), the interaction is present for singular-dominant nouns, but for pluraldominant nouns it is only present in the participant analysis. However, whichever baseline is considered, singular- and plural-dominant nouns behave differently, and they do so in a way that is compatible with the idea of determiner competition being modulated by singularversus plural-dominance. In the General Discussion, we will introduce an extension of the primed unitised activation hypothesis (Alario \& Caramazza, 2002) that accounts for the pattern of results obtained in Experiments 1 and 2 .

\section{General discussion}

The descriptive data show a parallel pattern of modulation effects of dominance in the diminutive- and the plural-experiments. In base-form-dominant and singular-dominant conditions, there is a cost for producing the determiner when the two morphological forms (base form/diminutive; singular/plural) require different determiners and no such cost or even a gain when they require the same determiner. In diminutive-dominant and pluraldominant conditions, there is likewise an interaction of Experiment, gender, and produced form. However, this interaction is due to a gain when the two morphological forms converge on the same determiner.

The fact that the modulation effect of dominance is parallel for the two morphological domains, diminutives and plurals, suggests that there is one common underlying mechanism for both morphological domains. Recall that for diminutives, we cannot decide whether the pat- 
tern is due to competition between abstract gender nodes or actual determiners as determiner competition always goes hand in hand with gender competition. For plural utterances, by contrast, the competition must concern singular and plural determiners as the gender of a given noun does not change when going from a singular to a plural form. ${ }^{6}$ Thus, the most parsimonious account is to assume that the critical interactions reflect competition between determiners in both morphological domains.

With respect to the modulating effect of dominance, none of our three scenarios (uniform processing, independent entries, and dominance driven access) can account for the observed data pattern. The observed interactions show that the singular base form becomes activated even when diminutive-dominant or plural-dominant nouns are produced in their dominant form. This comes closest to uniform processing. However, this hypothesis predicts that there are always costs when producing the diminutive of a $d e$-word and the plural of a het-word. Obviously, this is not the case. The most auspicious explanation would be that the underlying mechanism is always the same, namely the coactivation of the determiner of the fundamental form (for the sake of brevity, base form and singular will be referred to as fundamentals). However, the preference of a noun to be used as a certain form, increases the amount of activity that this form gives to its corresponding determiner. These differences in activity can be responsible for the varying form of the Experiment by gender by produced-form interactions. This explanation is backed up by data in German obtained by Schriefers et al. (2002), showing that the pattern of facilitation and inhibition effects when going from singular to plural NPs shifts as a function of the experimental context: With an equal proportion of different determiners in the experiment (i.e., when there were more singular responses than plural responses), they found inhibition for the plurals of masculine (singular: der, plural: die) and neutral words (singular: das, plural: die) and no difference in naming latencies for feminine words (singular and plural: die). In an experimental set-up with an equal proportion of singulars

\footnotetext{
${ }^{6}$ For a language like Dutch, where no gender distinctions are made for determiners or inflected adjectives in the plural, it could even be assumed that the gender feature is neutralised in the plural. Still, our conclusions hold, because also in this case the pattern of results of Experiment 2 points to determiner competition and not to gender competition: If the gender feature is neutralised in the plural, then there will not be any gender competition - or just as much gender competition for het-words as for $d e$-words, namely the competition between a specified and a neutralised gender feature. By contrast, on the level of actual determiners, het-words demand different determiners in the singular and in the plural, and this conflict is reflected in the reaction time data.
}

and plurals (i.e., there were more responses requiring the determiner die than responses requiring the other two determiners), they found facilitation for the plurals of feminine gender words and small or no inhibition for words of masculine and neuter gender. Thus, while the pattern shifted by an additive factor, the interaction of produced form (singular vs. plural) and gender remained constant. This is also true in the present experiments. Although we always used an equal proportion of the determiners de and het, apparently an inherent property of the word, namely dominance, has a similar effect as the manipulation of the relative proportion of singular and plural forms within an experiment. If the diminutive or plural forms, respectively, have a low dominance value, the descriptive pattern is similar to Schriefers et al.'s "low-plural" proportion. If the diminutive or plural forms have a high dominance value, the pattern mirrors Schriefers et al.'s "high-plural" proportion. Thus, the extrinsic proportion manipulation has a similar effect as intrinsic dominance properties of words. A preference to produce a word in one form and not the other ("dominance") is presumably learnt by linguistic exposure. Apparently, it can also - to a lesser extent - be learnt in the course of an experiment. This observation is bolstered up by experiments of Dell, Reed, Adams, and Meyer (2000) and Bock and Griffin (2000) who show that a similar learning mechanism is at work with phonological or syntactic regularities.

In the remainder of the General Discussion, we are going to formalise our conclusion that there is always determiner competition but that its appearance changes according to the activation patterns it operates on. We use the primed unitised activation account of Alario and Caramazza (2002) as point of departure. We will first look at diminutives and base forms and then extend the model to singular and plural NPs. Following Janssen and Caramazza (2003), we assume that the following features play a role in the selection of the correct determiner: gender of base form (with the possible values common and neuter gender), and morphological form (with the possible values base form and diminutive). The features definiteness and number also affect determiner selection. However, in the domain of base forms and diminutives, when participants produce definite determiner NPs in the singular, we can neglect these features as they do not lead to any differential predictions between the conditions involved.

How do these features become activated? A conceptual input activates corresponding lexical representations which will in their turn activate the corresponding determiners. We cannot, based on our data, make a claim about whether fundamental and alternative form are distinct but connected entries or shared entries. It is necessary, however, that the production of an alternative form activates the fundamental form. Furthermore, this activation goes all the way 
down to the corresponding determiner. As suggested by Alario and Caramazza (2002), the activation is collected in a frame. The specific combination of activated features determines the speed of determiner selection.

In our proposal, each feature activates a corresponding determiner, and the eventual combination of features in a frame activates its corresponding determiner. More specifically, the feature common gender of base form activates the determiner de, neuter gender the determiner het, and the feature diminutive the determiner het. The feature base form does not activate a specific determiner because the determiner of a base form depends on its gender. Finally, the feature frame $[$ common + base form $]$ activates de, and the frames [common + diminutive], [neuter + base form], and [neuter + diminutive $]$ activate het.

So far, we follow the scenario proposed by Alario and Caramazza (2002), and Janssen and Caramazza (2003). We will now extend this account in three steps. First, we will assume that the amount of activation that the feature diminutive can pass to its corresponding determiner varies as a function of dominance. Second, we will show how this variation affects the net activation of the target determiner in a specific phrase. Finally, we will show that the resulting activation difference between base form determiner and diminutive determiner in the different experimental conditions is highly correlated with the experimentally obtained latency costs and gains. Note that we do not have the pretence to introduce a full-blown mathematical or computational model. Rather, we translate assumptions about activation into numbers and look if we can thereby explain our experimental results. We use only two assumptions: (1) Frames contribute more to the determiner selection process than individual features. This assumption reflects the fact that, whereas all individual features contribute to the activation process, it is the frame that eventually governs determiner selection. (2) Dominance modulates the activation according to its strength as assessed by CELEX-proportions or individual ratings.

We start with the assumption that each individual feature receives the same amount of activation when triggered. We arbitrarily assign the value 1 (activationunit) to this activation. It will be sent to the corresponding determiner. The frame, being the crucial factor in determiner selection, will pass on two activation units to its corresponding determiner. Dominance is implemented as an additive modifier to the amount of activation the feature diminutive passes on to the determiner het. By default, the diminutive feature sends one activation-unit to the determiner het. To this activation unit, a dominance dependent value, hereafter called diminutive-modifier, is added.

The computation of the diminutive-modifier is based on the assignment of items to the dominance groups as shown in Table 1. The range of ratings for base-formdominant items is $1.07-1.87$, the range for diminutive- dominant items is $4.00-6.13$. The scale went from 1 to 7. We used the median of the ratings, not the median of the scale as the point where an item is regarded as truly neutral. This value is 2.93 - for ease of calculation we used the value 3 . The diminutive-modifier is the deviation from this point. Thus, for the group of baseform-dominant de-words (mean rating $=1.31$ ), the diminutive-modifier is $(1.31-3)=-1.69$. The modifier for base-form-dominant het-words is $(1.32-3)=-1.68$. The modifier for diminutive-dominant $d e$-words is $(4.24-3)=1.24$. Finally, the modifier for diminutivedominant het-words is $(4.95-3)=1.95$.

The next step is to calculate the net activation a target determiner receives. Here, "net activation" signifies the sum of all activation the eventual target determiner receives minus the sum of all activation the competing determiner receives. For base-form-dominant $d e$-words as base form, de receives 1 unit from the feature common gender, and 2 units from the frame [common gender + base form], that is a net activation of 3 . For base-form-dominant $d e$-words as diminutives, the target determiner het receives $1-1.69$ [modifier] $=-0.69$ activation-units from the feature diminutive and 2 activationunits from the frame [common gender + diminutive]. The non-target determiner de receives 1 activation-unit from the feature common gender. The net activation for het is $-0.69+2-1=0.31$. We assume that the relation between the activation of the target determiner and its competitor provides a measure of the selection difficulties of the target determiner. Here we do this in terms of the net activation of the target. However, the basic idea is akin to Luce's choice ratios, used in computational models of lexical access in language production (e.g. Levelt, Roelofs, \& Meyer, 1999).

The target determiner in the base form phrase receives an activation of 3 , and the target determiner in the diminutive phrase of 0.31 , involving a -2.69 activation disadvantage. This disadvantage for diminutives relative to base forms is reflected in a naming latency cost of $56 \mathrm{~ms}$ in the experimental data pattern. The reaction time costs and gains used in the model are taken from the difference values of Experiments $1 \mathrm{a}$ and $1 \mathrm{~b}$.

In the same way we can calculate the activation costs or benefits for diminutives relative to base forms for the other three item groups: For base-form-dominant het-words a -0.68 activation disadvantage and a nonsignificant gain of $30 \mathrm{~ms}$ in naming latencies; for diminutive-dominant $d e$-words a 0.24 activation advantage and a non-significant gain of $26 \mathrm{~ms}$ in naming latencies; and for diminutive-dominant het-words a 2.95 activation advantage and a naming latency gain of $108 \mathrm{~ms}$ (see Appendix $\mathrm{C}$ for details). The correlation of these four activation (dis-)advantages for selecting the target determiner with the respective latency costs and gains is $r=-.98, p<.05$, indicating that a high diminutive advantage in activation (reflected in a positive value) 
leads to faster naming latencies for diminutive NPs than base form NPs (reflected in a negative naming latency difference).

The results of this extended primed unitised activation account reflect the experimentally obtained results well. Furthermore, the extrapolation of the unitised activation account shows that when we use the same mechanism throughout, it surfaces differently because of differences in activation levels. In other words: There is always determiner competition, but it does not always show up as inhibition. So far, we correlated the mean activation for the four different word types with the mean latency cost or gain for producing a diminutive relative to its base form. If the process of determiner selection is modulated by means of underlying activation patterns, we should also observe a gradual change in naming latencies as a function of the individual diminutive dominance of a produced word. The more diminutive-dominant an item, the less its corresponding base form (and its determiner) will be activated, leading to weaker determiner competition. Computing the activation (dis-)advantage not for a factorial group of items, but for every single item, including the neutral fillers, and correlating it with the corresponding latency gain/cost, gives a correlation of $r=-.62$, $p<.001$. Our material was not constructed for a correlation analysis but for a factorial design: Base-form- and diminutive-dominant items were deliberately chosen to form highly homogenous dominance groups that should be as distinct as possible. However, the fillers were a much less homogeneous group with respect to dominance, with the only restriction that they should not overlap with the dominance of the two groups of experimental items. Therefore, inclusion of these fillers makes dominance a more continuous variable with values spreading out over the whole scale, making a correlation analysis more adequate. This correlation analysis supports the notion of a gradual change in reaction time patterns as a function of the individual diminutive dominance of a produced word.

Next, we use our extension of primed unitised activation for singular and plural nouns. We proceed in a similar way as for the base form and diminutive data. A target determiner accumulates activation from the features gender of base form, number (note that when the number feature is singular, it does not provide information about the determiner) and the frame [number + gender of base form]. The number feature passes on activation to the determiner $d e$ when a word is produced as a plural. As before, a modifier is used to modulate the default activation value 1 of the number feature. The modifier was calculated based on CELEX frequency counts, not on ratings, because in Experiment 2 we had used these frequency counts to determine dominance. However, we also had 15 native speakers of Dutch provide subjective ratings of singular and plural dominance of our items. These subjective ratings and CELEX dominance values correlate significantly $(r=0.64)$. The model gives virtually the same results for the plural modifier based on CELEX frequencies or for the plural modifier based on subjective dominance ratings. Here we will report values based on CELEX. Appendix D shows in detail how values were calculated. Computing the activation difference between selecting the determiner for a word as a singular and as a plural and correlating the resulting activation (dis-) advantages with the naming latency costs or gains, gives a correlation of $-.96, p<.05$. We did not include neutral fillers in Experiment 2, therefore computation of the correlation between activation (dis-)advantages and naming latency costs and gains was only possible for the dichotomous dominance groups but not for individual items.

To summarise, we show that dominance has a clear effect on determiner selection in the production of NPs in two different morphological domains. However, it is not necessary to assume different mechanisms of determiner selection as a function of dominance. Rather, the empirical data can be explained within one theoretical framework by assuming underlying activation patterns that reflect the relative dominance of the different morphological forms of a noun. It is also important to mention that the proposed mechanism for determiner selection is independent of assumptions about the representation of diminutives and plurals in the mental lexicon. That is, the proposed selection mechanism can work in the same way independent of whether plurals and diminutives are assumed to have separate full representations in the mental lexicon, or whether they are derived by rule from a base form. ${ }^{7}$ For both cases, the present data show that the singular base form is activated when producing diminutive and plural NPs. This activation goes down to the level of the associated determiner, even in cases where the singular base form has a very low dominance value.

\section{Appendix A. Experimental items Experiment 1}

\section{Base-form-dominant de-words}

Fakkel (torch), gordel (belt), hengel (fishing rod), kano (canoe), mug (mosquito), pinda (peanut), schommel (swing), tractor (tractor), troon (thrown), and waaier (fan).

\section{Base-form-dominant het-words}

Fornuis (cooker), geweer (rifle), gewei (antler), kanon (canon), paleis (palace), pincet (tweezers), pistool (pistol), skelet (skeleton), web (web), and zwaard (sword).

\footnotetext{
${ }^{7}$ Note in this context that the neutrality of the proposed mechanism with regard to representation assumptions is shared by the uniform processing hypothesis, but not by the independent entries and dominance driven accounts. The latter two (implicitly) assume separate representations for plurals or diminutives when they are dominant.
} 


\section{Diminutive-dominant de-words}

Boon (bean), boot (boat), kaars (candle), knoop (button), lepel (spoon), mand (basket), muis (mouse), twijg (branch), worst (sausage), and zak (bag).

\section{Diminutive-dominant het-words}

Blad (leaf), blik (can), dorp (village), kado (present), kalf (calf), konijn (rabbit), kleed (rug), kuiken (chick), lam (lamb), and touw (rope).

\section{Neutral de-words}

Emmer (bucket), haan (cock), laars (boot), molen (windmill), sigaar (cigar), sleutel (key), sok (sock), struik (bush), taart (cake), and tent (tent).

\section{Neutral het-words}

Bed (bed), boek (book), bord (plate), dak (roof), eiland (island), hart (heart), huis (house), schaap (sheep), schilderij (painting), and wiel (wheel).

\section{Appendix B. Experimental items Experiment 2}

\section{Singular-dominant de-words}

Bril (glasses), broek (trousers), fles (bottle), kachel (oven), kerk (church), kroon (crown), molen (windmill), muts (cap), tafel (table), and trui (jumper).

\section{Singular-dominant het-words}

Altaar (altar), anker (anchor), gebit (dentition), glas (glass), hart (heart), hek (fence), kado (present), palet (palette), pistool (pistol), and slot (bolt).

\section{Plural-dominant de-words}

Banaan (banana), boom (tree), koe (cow), laars (boot), spijker (nail), tak (branch), tomaat (tomate), ui (onion), vinger (finger), and vogel (bird).

\section{Plural-dominant het-words}

Atoom (atom), been (leg), bot (bone), ei (egg), insekt (insect), kanon (canon), oor (ear), schaap (sheep), varken (pig), and wiel (wheel).

\section{Appendix C. Activation (dis-)advantages for Experiment 1}

The first table of Appendix C shows the computation of net activation-units for selecting base form and diminutive determiners. Sources of activation are gender (gen), form, dominance (dom), and the feature frame, whereby dominance modulates the form feature (indicated as [form-dom]).

The second table of Appendix C shows the activation (dis-) advantage for going from a base form to a diminutive determiner and the corresponding naming latency cost or benefit.
Net activation of target determiner (=activation target determiner minus activation competing determiner)

\begin{tabular}{lllll}
\hline & gen & [form-dom] & frame & net \\
\hline de bf-dom as bf & 1 de & - & 2 de & 3 de \\
de bf-dom as dim & 1 de & $(1-1.69)$ het & 2 het & 0.31 het \\
het bf-dom as bf & 1 het & - & 2 het & 3 het \\
het bf-dom as dim & 1 het & $(1-1.68)$ het & 2 het & 2.32 het \\
de dim-dom as bf & 1 de & - & 2 de & 3 de \\
de dim-dom as dim & 1 de & $(1+1.24)$ het & 2 het & 3.24 het \\
het dim-dom as bf & 1 het & - & 2 het & 3 het \\
het dim-dom as dim & 1 het & $(1+1.95)$ het & 2 het & 5.95 het \\
\hline
\end{tabular}

Note. de: word with base form of common gender; het: word with base form of neuter gender; bf-dom: base form dominant; and dim-dom: diminutive dominant.

Activation (dis-)advantage and naming latency (RT) costs/ benefits

\begin{tabular}{lcc}
\hline & Activation $(\operatorname{dim}-\mathrm{bf})$ & $\mathrm{RT}(\operatorname{dim}-\mathrm{bf})$ \\
\hline de bf-dom & -2.69 & 56 \\
de dim-dom & -0.68 & -30 \\
het bf-dom & 0.24 & -26 \\
het dim-dom & 2.95 & -108 \\
\hline
\end{tabular}

Note. de: word with base form of common gender; het: word with base form of neuter gender; bf-dom: base form dominant; and dim-dom: diminutive dominant.

\section{Appendix D. Activation (dis-)advantages for Experiment 2}

The sources that contribute to the activation of a determiner are the features gender, number, and the frame. The number feature only conveys determiner information for the plural, when it sends activation to the determiner de. This activation is 1 by default but is modified by the logarithmic dominance value. The logarithmic value was used for the following reason: Dominance was assessed by dividing an item's frequency as a singular by its frequency as a plural. Thus, singular-dominant nouns can have values from 1 to infinity, whereas plural-dominant noun have values between 0 and 1 . Therefore we could not utilise the absolute values. The logarithmic dominance value is subtracted from 1 because, due to how it was computed, it is positive for singular-dominant nouns and negative for plural-dominant nouns. The first table of Appendix D shows the dominance values and their logarithmic values.

The second table of Appendix D shows how the net activation for singular and plural determiners is computed. Sources of activation (net) are gender (gen), number (num), dominance (dom), and the feature frame, whereby dominance modulates the number feature.

The third table of Appendix D shows the activation (dis-)advantage for going from a singular to a plural determiner and the corresponding naming latency cost or benefit. 


\begin{tabular}{lll}
\hline & Dominance value & Logarithmic dominance value \\
\hline de sg-dom & 11.42 & 1.06 \\
het sg-dom & 12.73 & 1.1 \\
de pl-dom & 0.55 & -0.26 \\
het pl-dom & 0.57 & -0.24 \\
\hline
\end{tabular}

Note. de: word of common gender; het: word of neuter gender; sg-dom: singular dominant; and pl-dom: plural dominant.

Net activation of target determiner (=activation target determiner minus activation competing determiner)

\begin{tabular}{lllll}
\hline & gen & {$[$ num-dom] } & frame & net \\
\hline de sg-dom as sg & $1 \mathrm{de}$ & - & $2 \mathrm{de}$ & $3 \mathrm{de}$ \\
de sg-dom as pl & $1 \mathrm{de}$ & {$[1-1.06] \mathrm{de}$} & $2 \mathrm{de}$ & $2.94 \mathrm{de}$ \\
het sg-dom as sg & 1 het & - & $2 \mathrm{het}$ & $3 \mathrm{het}$ \\
het sg-dom as pl & 1 het & {$[1-1.1] \mathrm{de}$} & $2 \mathrm{de}$ & $0.9 \mathrm{de}$ \\
de pl-dom as sg & $1 \mathrm{de}$ & - & $2 \mathrm{de}$ & $3 \mathrm{de}$ \\
de pl-dom as pl & $1 \mathrm{de}$ & {$[1+0.26] \mathrm{de}$} & $2 \mathrm{de}$ & $4.26 \mathrm{de}$ \\
het pl-dom as sg & 1 het & - & $2 \mathrm{het}$ & 3 het \\
het pl-dom as pl & 1 het & {$[1+0.24] \mathrm{de}$} & $2 \mathrm{de}$ & $2.24 \mathrm{de}$ \\
\hline
\end{tabular}

Note. de: word of common gender; het: word of neuter gender; sg-dom: singular dominant; and pl-dom: plural dominant.

Activation (dis-)advantage and naming latency (RT) costs/ benefits

\begin{tabular}{lll}
\hline Condition & Activation (plur - sing) & RT (plur $-\operatorname{sing}$ ) \\
\hline de sg-dom & -0.06 & -24 \\
het sg-dom & -2.1 & 18 \\
de pl-dom & 1.26 & -88 \\
het pl-dom & -0.76 & -28
\end{tabular}

Note. de: word of common gender; het: word of neuter gender; sg-dom: singular dominant; and pl-dom: plural dominant.

\section{References}

Alario, F.-X., \& Caramazza, A. (2002). The production of determiners: Evidence from French. Cognition, 82, 179-223.

Baayen, H. R., Dijkstra, T., \& Schreuder, R. (1997). Singulars and plurals in Dutch: Evidence for a parallel dual-route model. Journal of Memory and Language, 37, 94-117.

Baayen, H. R., Piepenbrock, R., \& van Rijn, H. (1993). The CELEX lexical database (CD-ROM). University of Pennsylvania, Philadelphia, PA: Linguistic Data Consortium.

Bakema, P., Defour, P., \& Geeraerts, D. (1993). De semantische structuur van het diminutief [The semantic structure of the diminutive]. Forum der Letteren, 34, 121-137.

Balota, D. A., \& Chumbley, J. I. (1985). The locus of wordfrequency effects in the pronunciation task: Lexical access and/or production?. Journal of Memory and Language, 24, 89-106.
Bock, K., \& Griffin, Z. M. (2000). The persistence of structural priming: Transient activation or implicit learning?. Journal of Experimental Psychology: General, 129, 177-192.

Bock, K., \& Levelt, W. (1994). Language production: Grammatical encoding. In M. A. Gernsbacher (Ed.), Handbook of psycholinguistics (pp. 945-984). San Diego, CA: Academic Press.

Booij, G., \& van Santen, A. (1998). Morfologie: De woordstructuur van het Nederlands (2nd ed.) [Morphology: The word structure of Dutch]. Amsterdam: Amsterdam University Press.

Dell, G. S., Reed, K. D., Adams, D. R., \& Meyer, A. S. (2000). Speech errors, phonotactic constraints, and implicit learning: A study of the role of experience in language production. Journal of Experimental Psychology: Learning, Memory, and Cognition, 26, 1355-1367.

Haas de, W., \& Trommelen, M. (1993). Morfologisch handboek van het Nederlands: een overzicht van de woordvorming [Morphological handbook of Dutch: An overview of word formation]. Gravenhage: SDU.

Janssen, N., \& Caramazza, A. (2003). The selection of closedclass words in noun phrase production: The case of Dutch determiners. Journal of Memory and Language, 48, 635-652.

Jescheniak, J. D., \& Levelt, W. J. M. (1994). Word frequency effects in speech production: Retrieval of syntactic information and of phonological form. Journal of Experimental Psychology: Learning, Memory, and Cognition, 20, 824-843.

La Heij, W., Mak, P., Sander, J., \& Willeboordse, E. (1998). The gender-congruency effect in picture-word tasks. Psychological Research, 61, 209-219.

Levelt, W. J. M. (1999). Models of word production. Trends in Cognitive Sciences, 3, 223-232.

Levelt, W. J. M., Roelofs, A., \& Meyer, A. S. (1999). A theory of lexical access in speech production. Behavioral and Brain Sciences, 22, 1-75.

Miozzo, M., \& Caramazza, A. (1999). The selection of determiners in noun phrase production. Journal of Experimental Psychology: Learning, Memory and Cognition, 25, 907-922.

Schiller, N. O., \& Caramazza, A. (2003). Grammatical feature selection in noun phrase production: Evidence from German and Dutch. Journal of Memory and Language, 48, 169-194.

Schriefers, H. (1993). Syntactic processes in the production of noun phrases. Journal of Experimental Psychology: Learning, Memory and Cognition, 19, 841-850.

Schriefers, H., Jescheniak, J. D., \& Hantsch, A. (2002). Determiner selection in noun phrase production. Journal of Experimental Psychology: Learning, Memory and Cognition, 28, 941-950.

Schriefers, H., Jescheniak, J. D., \& Hantsch, A. (in press). Selection of gender-marked morphemes in speech production. Journal of Experimental Psychology: Learning, Memory and Cognition.

Schriefers, H., \& Teruel, E. (2000). Grammatical gender in noun phrase production: The gender interference effect in German. Journal of Experimental Psychology: Learning, Memory and Cognition, 26, 1368-1377.

van Berkum, J. J. A. (1997). Syntactic processes in speech production: The retrieval of grammatical gender. Cognition, 64, 115-152. 